Arab Journal of Urology

(Official Journal of the Arab Association of Urology)

\title{
URINARY TRACT INFECTION
}

REVIEW

\section{Emphysematous pyelonephritis: Time for a management plan with an evidence-based approach}

\author{
Omar M. Aboumarzouk ${ }^{\text {a,* }}$, Owen Hughes ${ }^{\text {b }}$, Krishna Narahari ${ }^{\text {b }}$, \\ Richard Coulthard $^{\text {b }}$, Howard Kynaston ${ }^{b}$, Piotr Chlosta ${ }^{c}$, Bhaskar Somani ${ }^{d}$ \\ a Islamic University of Gaza, College of Medicine, Gaza, Palestine \\ ${ }^{\mathrm{b}}$ Department of Urology, University Hospital of Wales, Heath Park, Cardiff, Wales, UK \\ c Department of Urology, Jagiellonian University, Cracow, Poland \\ d Department of Urology, University Hospital of Southampton NHS Foundation Trust, Southampton, UK
}

Received 10 July 2013, Received in revised form 21 September 2013, Accepted 22 September 2013

Available online 19 November 2013

\section{KEYWORDS \\ Emphysematous pyelonephritis; Infection; Pyelonephritis; Emergency nephrec- tomy; \\ Percutaneous drainage

ABBREVIATIONS
EPN, emphysematous
pyelonephritis;
PCD, percutaneous
drainage;

\begin{abstract}
Introduction: Emphysematous pyelonephritis (EPN) is a life-threatening necrotising kidney infection, but there is no consensus on the best management.

Methods: We systematically reviewed previous articles published from 1980 to 2013 that included studies reporting on EPN, and applying the Cochrane guidelines, we conducted a meta-analysis of the results.

Results: In all, 32 studies were included, with results for 628 patients (mean age 56.6 years, range 33.8-79.9). There were 462 women, outnumbering men by $3: 1$. Diabetes was present in $85 \%$ of the cases. Fevers and rigor $(74.7 \%)$, pyuria $(78.2 \%)$ and pain $(70.4 \%)$ were the most common symptoms. Shock was associated with $54.4 \%$ of deaths while obstructive uropathy was associated with $15.1 \%$ of deaths. Computed tomography was diagnostic in all the cases. Percutaneous drainage (PCD) and medical management (MM) alone were associated with a significantly lower mortality rate than was emergency nephrectomy (EN), with an odds ratio $(95 \%$ confidence interval) for PCD vs. EN of $3.13(1.89-5.16 ; P<0.001)$, for EN vs. MM of 2.84 (1.62-4.99; $P=0.001)$, and of $0.91(0.53-1.56 ; P=0.73$, i.e., no difference) for
\end{abstract}

\footnotetext{
* Corresponding author. Tel.: +44 7886885677.

E-mail address: aboumarzouk@gmail.com (O.M. Aboumarzouk).

Peer review under responsibility of Arab Association of Urology.

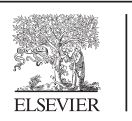

Production and hosting by Elsevier
} 
MM, medical management;

EN, nephrectomy;

OD, open drainage;

DM, diabetes mellitus;

OR, odds ratio
PCD vs. MM. Open drainage also had a significantly lower mortality rate than EN, with a ratio of $0.12(0.02-0.91 ; P<0.04)$.

Conclusion: The overall mortality rate was $\approx 18 \%$; shock was associated with a high mortality rate and therefore should be managed aggressively. PCD and MM were associated with significantly higher survival rates than EN, and therefore EN should only be considered if the patient does not improve despite other treatments. (C) 2013 Production and hosting by Elsevier B.V. on behalf of Arab Association of Urology.

\section{Introduction}

Emphysematous pyelonephritis (EPN) is a rare type of necrotising infection, and as such is life-threatening if not treated promptly. It is defined as an acute and severe infection of the renal parenchyma and peri-renal tissue, which results in gas within the renal parenchyma, collecting system or perinephric tissue [1-5]. Although it was first described in 1898, the term EPN was first used in 1962 [5]. It is more common in patients with diabetes mellitus (DM) or patients who are immunocompromised, with a female:male predominance of $4: 1$ and a mean (range) age of 57 (24-83) years [5,6].

Although it is a life-threatening illness with a mortality rate of up to $50 \%$ there is no consensus on the best management of these patients [5]. The main focus of treatment is an emergency nephrectomy (EN), percutaneous drainage (PCD), or medical management (MM), with or with no stenting of the urinary tract. Some reports recommend that EN should be the mainstay of treatment and not be delayed [2,3], but others recommended a more conservative approach with PCD [68], and a purely conservative approach with MM alone has also been advocated [9-11], which further increases the management conundrum.

To aid in the decision, a few reports have been published with mortality rates stratified by risk variables, delineating which patients need more aggressive management than others [10,12-16]. However, these were not only based on relatively few patients, but between the studies they also had varying results for the same risk variable. Furthermore, other studies attempted to delineate the management based on the CT findings, but these too were also based on few patients and were not based on robust classifications [3,7,17-19].

Nonetheless, because there is no substantive evidence, these reports remain the only available guide to aid clinicians in managing EPN. Thus the aim of this study was to systematically review previous reports and, using a meta-analysis, to determine the mortality rate of each treatment from the available series. Furthermore, we aimed to stratify the prognostic factors across the published studies to determine the specific factors for EPN and their association with death, and to describe the clinical and laboratory presentation of patients with EPN.

\section{Methods}

\section{Search strategy and study selection}

The systematic review was conducted using the Cochrane review guidelines, and cross checked with the PRISMA guidelines. The search strategy was devised to find relevant studies from Medline (1980 to February 2013), EMBASE (1980 to February 2013), the Cochrane Central Register of Controlled Trials (in The Cochrane Library, Issue 1 to 2013), CINAHL (1980 to February 2013), www.clinicaltrials.gov, Google Scholar and individual urological journals. The search was made on 2 February 2013.

The search terms used included: 'emphysematous pyelonephritis', 'emphysematous nephritis', 'emphysematous pyelitis', 'necrotising renal infection', and 'gaseous renal infection'. Papers in languages other than English were included if the data were extractable, and the references of papers were evaluated for potential inclusion.

Three reviewers independently identified all studies that met the inclusion criteria for evaluation. Three reviewers independently extracted the data for inclusion. One reviewer correlated all data extraction. Disagreement between the reviewers was resolved by consensus. A qualified statistician reviewed all the data and conducted the statistical analysis.

\section{Data extraction and analysis}

Studies reporting on four or more cases of EPN were included. The main aim was to assess the mortality rate associated with EPN, depending on the various treatments offered. The three main treatments reviewed were EN, PCD and conservative MM. Further treatments were also compared where reported. The secondary outcome was to assess the more common risk factors associated with death, and the most common presenting symptoms, diagnostic investigations, and most common causative organisms. Where available, patients with risk factors for death were compared to those with no risk factors. Furthermore, the risk of death was assessed based on the different types of classification of EPN. The Wan classification divides EPN into type I (severe) and type II (mild) [4], with type I defined as parenchymal destruction with either total absence of fluid content on $\mathrm{CT}$, or the presence of a streaky gas pattern regard- 
Table 1 The studies included and patient demographics.

\begin{tabular}{|c|c|c|c|c|}
\hline Ref. & Period & M:F & Mean (range) Age, years & R:L:bilat:graft \\
\hline [1] & NM & $8: 3$ & 56.3 & NM \\
\hline [2] & $1980-95$ & $5: 15$ & 55 & $7: 12: 1$ \\
\hline [3] & 1991-99 & $1: 20$ & $61(11.1)$ & $9: 11: 1$ \\
\hline [6] & $2000-2010$ & $8: 25$ & $51(10.9)$ & $12: 15: 3$ \\
\hline [7] & $1984-95$ & $7: 18$ & 60.6 & $13: 12$ \\
\hline [8] & 1993-2004 & $3: 23$ & $58.7(12.7)$ & $13: 11: 2$ \\
\hline [10] & 1995-2009 & $11: 12$ & $62.8(17.1)$ & $8: 13: 1: 1$ \\
\hline [11] & 2008-2011 & $4: 4$ & $49.63(8.99)$ & $?: ?: 4$ \\
\hline [12] & 2004-2008 & $6: 33$ & $57(7.2)$ & $6: 28: 4$ \\
\hline [13] & 2005-2010 & 1:17 & 52.4 & NM \\
\hline [14] & $1986-93$ & $5: 33$ & 54.7 & $?: ?: 2$ \\
\hline [15] & $2001-2007$ & 3:13 & $61.2(11.5)$ & $6: 9: 1$ \\
\hline [16] & $2001-2007$ & $3: 16$ & $43.6(8.9)$ & $3: 11: 5$ \\
\hline [17] & $2000-2009$ & $7: 17$ & 61.8 & $11: 11: 2$ \\
\hline [18] & $1989-97$ & $7: 41$ & 60 & $12: 32: 4$ \\
\hline [19] & $1986-96$ & $7: 21$ & 61.6 & $13: 14: 1$ \\
\hline [20] & $2001-2007$ & $22: 19$ & $55(7.3)$ & $19: 13: 8$ \\
\hline [21] & 2005-2009 & $10: 18$ & NM & NM \\
\hline [24] & 1996-2004 & $1: 6$ & 44.5 & $2: 5$ \\
\hline [25] & $1980-85$ & $3: 10$ & 53 & $7: 5: 1$ \\
\hline [26] & NM & $2: 3$ & $53(4.77)$ & $\mathrm{NM}$ \\
\hline [27] & 2006-2010 & $3: 10$ & NM & $5: 4: 4$ \\
\hline [28] & $1992-2002$ & $1: 9$ & 61.2 & NM \\
\hline [29] & 1987-2009 & $10: 20$ & 58.5 & $9: 20: 1$ \\
\hline [30] & 1987-2004 & $6: 15$ & 54.6 & $6: 14: 1$ \\
\hline [31] & NM & $2: 3$ & $51(16.39)$ & $3: 2$ \\
\hline [32] & 2003-2005 & $7: 13$ & $54.4(20.6)$ & 10:06:2 \\
\hline [33] & NM & $4: 4$ & NM & NM \\
\hline [34] & $1986-91$ & $2: 2$ & $62(11.34)$ & $2: 2$ \\
\hline [35] & NM & $1: 3$ & $51.25(10.21)$ & $3: 1$ \\
\hline [36] & 1998-99 & $1: 5$ & $63.8(13.63)$ & $3: 2$ \\
\hline [37] & $1986-2004$ & $5: 12$ & 52 & $7: 8: 2$ \\
\hline
\end{tabular}

$\mathrm{NM}$, not mentioned.

less of the absence or presence of bubbly or loculated gas [4]. Type II was defined as the presence of renal or perirenal fluid in association with a bubbly or loculated gas pattern, or as gas in the collecting system, with acute bacterial nephritis or renal or perirenal fluid containing an abscess [4]. The Huang classification is more detailed, whereby class I EPN is defined as gas in the collecting system only, class II as gas in the renal parenchyma with no extension to the extrarenal space, class IIIa as extension of gas or abscess to the perinephric space, class IIIb as extension of gas or abscess to the pararenal space, and class IV as bilateral EPN or EPN in a solitary kidney [18]. We compare the two classifications. As Huang classes I and II are considered mild, and classes III and IV severe, we grouped them in this way, as adopted by a few of the studies $[12,16,20,21]$.

The following variables were extracted from each study: patient demographics, length of hospital stay, presenting symptoms, diagnostic investigations, culture results, laboratory findings, treatment, and mortality rate. Only similar results that could be pooled from the included studies were meta-analysed.

For continuous data, a Mantel-Haenszel chi-square test was used and expressed as the mean difference with
Table 2 Symptoms and the organisms cultured.

\begin{tabular}{ll}
\hline Symptoms & $n /$ total $n(\%)$ \\
\hline Pyuria & $161 / 206(78.2)$ \\
Fevers and rigors & $316 / 423(74.7)$ \\
Pain & $269 / 382(70.4)$ \\
Haematuria & $40 / 136(29.4)$ \\
Shock & $104 / 423(24.6)$ \\
Obstructive uropathy & $197 / 572(34.4)$ \\
Organism cultured & \\
Blood culture & \\
Escherichia coli & \\
Klebsiella pneumoniae & $186 / 351(53)$ \\
Proteus sp. & $27 / 157(17.2)$ \\
Urine culture & $2 / 39(5.1)$ \\
Escherichia coli & \\
Klebsiella pneumoniae & \\
Pseudomonas sp. & $347 / 552(62.9)$ \\
Proteus & $81 / 416(19.5)$ \\
Pus culture & $6 / 102(5.9)$ \\
Escherichia coli & $9 / 139(6.5)$ \\
Klebsiella pneumoniae & \\
Negative cultures & $115 / 208(55.3)$ \\
Blood & $26 / 142(18.3)$ \\
Urine & \\
Pus & $99 / 339(29.2)$ \\
& $68 / 307(22.2)$ \\
\hline & $8 / 87(9.2)$ \\
\hline
\end{tabular}

95\% CI, and for dichotomous data an inverse variance was used and expressed as the odds ratio (OR) with $95 \%$ CI. In both cases $P<0.05$ was considered to indicate significance.

Heterogeneity was analysed using a chi-squared test on $(N-1)$ degrees of freedom, with an $\alpha$ of 0.05 used to denote statistical significance, and with the $I^{2}$ test [22], where $I^{2}$ values of $25 \%, 50 \%$ and $75 \%$ correspond to low, medium and high levels of heterogeneity. A fixed-effect model was used unless there was statistically significant high heterogeneity (where $I^{2}>75 \%$ was considered as significantly high heterogeneity) between studies. A random-effects model was used if there was heterogeneity.

The methodological quality of the studies included in the meta-analysis was assessed as described in the Cochrane handbook $[22,23]$, and the quality assessment was plotted.

\section{Results}

The search identified 504 studies, of which 420 were excluded due to irrelevance based on titles, and 36 excluded due to irrelevance based on the abstracts (Fig. 1). Full reports were evaluated in 48 studies, of which 32 were included in the systematic review [13,6-8,10-21,24-37]. Most of the studies were published within the last 10 years, reflecting the increased awareness of EPN and the associated controversy. After reading the full reports, 16 studies were excluded for various reasons [4,5,9,38-50]; eight were case reports 
Table 3 Treatments and associated mortality rates, with the risk comparisons of treatments.

\begin{tabular}{|c|c|c|c|}
\hline Treatment & No. of deaths/total (\%) & Comparison, OR $(95 \% \mathrm{CI})$ & $P$ \\
\hline EN & $42 / 126(33.3)$ & & \\
\hline PCD & $39 / 283(13.8)$ & & \\
\hline MM & $25 / 167(15)$ & & \\
\hline OD & $1 / 18(6)$ & & \\
\hline PCD followed by DN & $5 / 47(10.6)$ & & \\
\hline MM followed by DN & $1 / 4$ & & \\
\hline EN vs. PCD & & $3.13(1.89-5.16)$ & $<0.001$ \\
\hline PCD vs. MM & & $0.91(0.53-1.56)$ & 0.73 \\
\hline EN vs. MM & & $2.84(1.62-4.99)$ & $<0.001$ \\
\hline PCD + DN vs. EN & & $0.24(0.09-0.65)$ & $<0.005$ \\
\hline $\mathrm{PCD}+\mathrm{DN}$ vs. $\mathrm{PCD}$ & & $0.74(0.28-2.00)$ & 0.56 \\
\hline PCD + DN vs. MM & & $0.68(0.24-1.88)$ & $<0.45$ \\
\hline OD vs. EN & & $0.12(0.02-0.91)$ & $<0.04$ \\
\hline OD vs. PCD & & $0.37(0.05-2.84)$ & $<0.34$ \\
\hline OD vs. MM & & $0.33(0.04,2.62)$ & $<0.3$ \\
\hline $\mathrm{OD}$ vs. $\mathrm{PCD}+\mathrm{DN}$ & & $0.49(0.05-4.55)$ & $<0.53$ \\
\hline
\end{tabular}

$[9,38,40,43,44,46,47,49]$, while five others were excluded as they were reporting on emphysematous cystitis $[41,42,45,48,50]$, and two were excluded as they were systematic reviews $[5,39]$. The final excluded study, Wan et al. [4] was excluded, as they reported an updated version of their data, which were included in this review [14].

\section{Characteristics of the included studies}

Although the search was conducted between 1980 and 2013, all except for seven of the 32 reports were published after 2000, with over half (18) published after 2007. The reporting study period was 1980-2011. All the studies reported patient age except for three $[1-3,6-8,10-20,24$ 26,28-32,34-37], and all studies reported on the diabetic status of the patients, while all but six reported on the mortality rate associated with DM $[1,3,8,10,11,13-$ 20,24-28,30-37]. All studies except eight reported on an aspect of the presenting symptom $[1-3,6-8,10,11,13-$ 19,21,24-30,32,34-37]. While 21 of the studies reported on whether or not the patients were in shock $[2,6,8,10$ 13,16-18,20,21,24-26,29-34], only 14 reported deaths associated with shock $[2,6,11,16,18,20,21,24,25,29$, 30,32-34]. The status of renal tract obstruction was reported by 28 of the studies $[1-3,6-8,11,12,14$ $21,24,25,27,29-37]$, but only 11 reported on deaths associated with obstruction $[1,8,11,15,18,25,31,33-36]$. All studies but eight reported on laterality $[2,3,6$ 8,10,12,15-20,24,25,27,29-32,34-37].

Twenty-three studies reported one or more aspects of the laboratory findings $[2,6,8,10-14,16,18,20,21,24$, 26,28-37], all reported on the diagnostic method used and the most common causative organism, and all re-

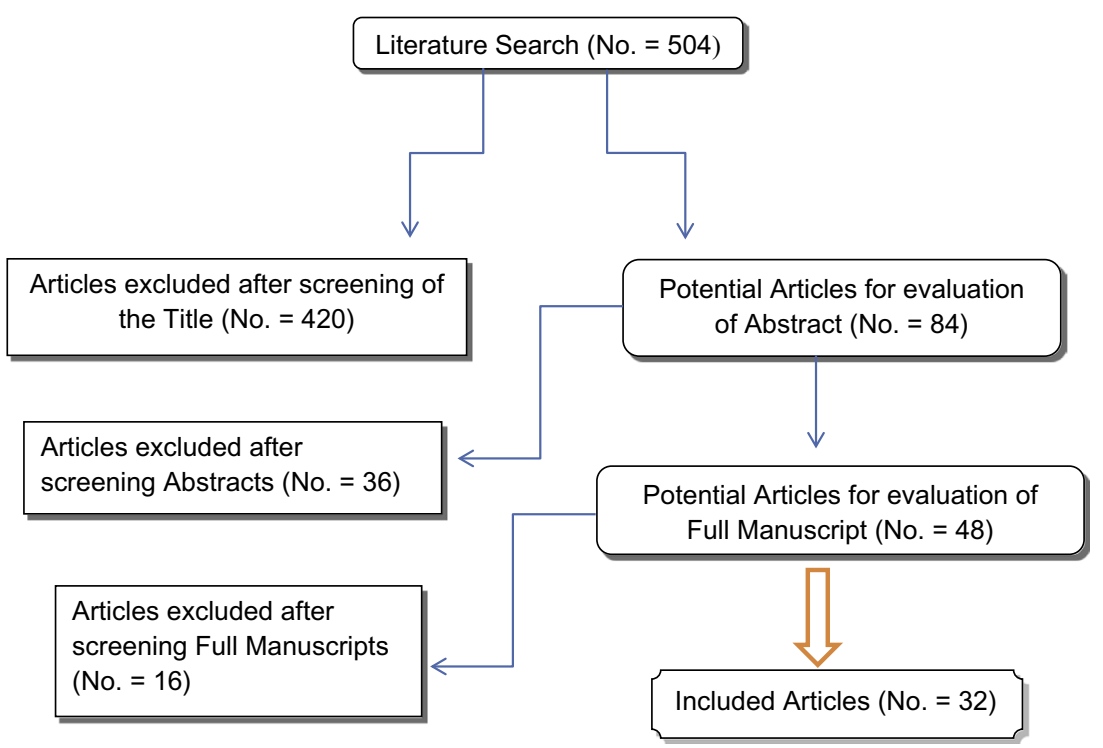

Fig. 1 The flowchart of the articles selected. 
Table 4 Risk factors and CT classifications with associated mortality rates.

\begin{tabular}{llll}
\hline Risk factors & Deaths/total reported & $P$ & OR (95\% CI) \\
\hline DM vs. no DM & $78 / 401$ vs. $12 / 58$ & 0.82 & $0.93(0.47-1.83)$ \\
Shock vs. no shock & $37 / 68$ vs. $15 / 215$ & $<0.001$ & $15.91(7.83-32.34)$ \\
Obstruction vs. no obstruction & $8 / 53$ vs. $30 / 97$ & 0.04 & $0.4(0.17-0.94)$ \\
Classifications & & & \\
Wan class I vs. II & $22 / 69$ vs. $16 / 120$ & 0.003 & $3.04(1.47-6.32)$ \\
Huang Class I + II & $6 / 119$ vs. $33 / 112$ & $<0.001$ & $0.13(0.05-0.32)$ \\
vs. III + IV & $22 / 69$ vs. $33 / 112$ & 0.73 & $0.02(-0.11-0.16)$ \\
Wan Class 1 vs. & & & \\
Huang Class III + IV & & \\
\hline
\end{tabular}

ported on the treatment used and accompanying mortality rate. Eight studies classified EPN according to the Wan classification $[3,7,13-15,18,27,28]$, whilst 11 classified EPN according to the Huang classification [6,10 $13,16,18,20,21,31,32]$, but two were not included in the pooled analysis as they had not reported which patients died according to which classification they were in $[6,13]$.

\section{Meta-analysis results}

In all there were 628 patients (mean age 56.6 years, range 33.8-79.9) (Table 1), comprising 166 men and 462 women, and $85.2 \%(535 / 628)$ of the patients had DM. Of the studies that reported laterality, $37.7 \%$ $(189 / 502)$ of patients had right-sided, vs. $52 \%(261 /$ $502)$ left-sided, EPN, with $10.2 \%$ (51/502) being bilaterally involved and $0.2 \%(1 / 502)$ being in a transplanted kidney.

Table 2 shows the incidence of symptoms in the patients, with pyuria being the most prevalent, followed by fevers and rigors, pain, haematuria, shock, and obstructive uropathy. Leucocytosis was present in $72.8 \%(214 / 294)$, thrombocytopenia in $40.3 \%(83 /$ 206), and deranged renal function (acute renal failure) in $45.2 \%(174 / 385)$. The organisms that were grown in culture are also listed in Table 2.

CT was accurate for detecting EPN in all 628 cases, whilst the accuracy rate for plain radiography was $53.2 \%(101 / 190)$ and for ultrasonography was $67.9 \%$ $(188 / 277)$.

In all there were 215 deaths $(18 \%)$ and Table 3 shows the mortality rates categorised according to the various treatments reported. For comparing the treatments, the OR $(95 \%$ CI) are also shown in Table 3, and the details of individual studies as Forest plots in Fig. 2, where studies that did not report evaluable data for the plot are not listed.

A subgroup analysis of the effect of the presence of risk factors on mortality is shown in Table 4 . The death rate was $19.5 \%$ in those with DM, vs. $20.7 \%$ in those without $(P=0.82)$. More patients who presented in shock $(54.4 \%)$ died than did those with no shock $(6.9 \%)(P<0.001)$. Fewer patients with obstructive uropathy $(15.1 \%)$ died than did those with no obstruction $(30.9 \%)(P=0.04)$ (Table 4$)$.

A subgroup analysis based on the CT classification showed that 189 patients were classified using the Wan system, with 69 of type I and 120 of type 2, of which $31.9 \%$ (22) died in the first group (severe EPN) vs. $13.3 \%$ (16) in the second (mild EPN) group (Table 4). The Huang classification was used for 231 patients, with 119 in classes I and II, and 112 in classes III and IV, of whom $5 \%$ (six) died in the first group (mild EPN) and $29.5 \%$ (33) died in the second (severe EPN) group (Table 4). Comparing the severe EPN groups of each classification showed no difference between the groups (Table 4).

\section{Methodological quality assessment}

All the included studies were case series, with no randomisation or control groups, and all reported on their centre's experience in managing patients with EPN. Based on the reviewing authors, the judgement of the hierarchy of evidence for each study was that the evidence was of low quality. However, collectively, the meta-analysis strengthens the level of evidence, despite being a meta-analysis of case series. It is difficult to conduct a study of emergency procedures, let alone randomise or even compare either of the methods to a control group. Hence it is unlikely that these types of studies will be conducted, and evidence-based guidance must be obtained from systematic reviews and metaanalysis of cases series such as these.

\section{Discussion}

The results of the meta-analysis showed that EPN has a 3:1 female to male ratio, and occurs predominantly in patients with DM, with an incidence of $85 \%$. The simple explanation is that this gives a combination of high tissue glucose concentrations, impaired tissue perfusion, and the presence of gas-producing organisms, the ideal environment for developing EPN [17]. The high tissue glucose level acts as a substrate for the micro-organisms to produce hydrogen and carbon dioxide by fermenta- 


\begin{tabular}{|c|c|c|c|c|c|c|c|c|}
\hline Study or Subgroup & \multicolumn{2}{|l|}{ DM } & \multicolumn{2}{|c|}{ NonDM } & Weight & $\begin{array}{c}\text { Odds Ratio } \\
\text { M-H, Fixed, } 95 \% \mathrm{Cl}\end{array}$ & \multicolumn{2}{|c|}{$\begin{array}{c}\text { Odds Ratio } \\
\text { M-H, Fixed, } 95 \% \mathrm{Cl}\end{array}$} \\
\hline Aswathaman 2008 & 9 & 38 & 0 & 3 & $5.1 \%$ & $2.25[0.11,47.70]$ & & \\
\hline Dubey 2011 & 1 & 4 & 0 & 1 & $3.7 \%$ & $1.29[0.03,53.51]$ & & \\
\hline Dutta $200 ?$ & 8 & 18 & 0 & 2 & $3.5 \%$ & $4.05[0.17,96.19]$ & & \\
\hline Huang 2000 & 7 & 46 & 2 & 2 & $29.4 \%$ & $0.04[0.00,0.87]$ & & \\
\hline Khaira 2009 & 2 & 16 & 0 & 3 & $5.1 \%$ & $1.21[0.05,31.22]$ & & \\
\hline Kuo 1999 & 2 & 25 & 1 & 3 & $12.2 \%$ & $0.17[0.01,2.87]$ & & \\
\hline Kuo 2009 & 2 & 13 & 2 & 3 & $20.4 \%$ & $0.09[0.01,1.55]$ & & \\
\hline Kuzgunbay 2011 & 2 & 21 & 0 & 3 & $5.6 \%$ & $0.90[0.04,22.97]$ & & \\
\hline Lin 2012 & 2 & 15 & 0 & 8 & $4.0 \%$ & $3.15[0.13,73.86]$ & & \\
\hline Overa-Posada 2012 & 2 & 12 & 0 & 6 & $3.9 \%$ & $3.10[0.13,75.18]$ & & \\
\hline Soo Park 2006 & 3 & 7 & 2 & 10 & $7.0 \%$ & $3.00[0.35,25.87]$ & & \\
\hline Total $(95 \% \mathrm{Cl})$ & & 215 & & 44 & $100.0 \%$ & $0.93[0.43,1.99]$ & & \\
\hline Total events & 40 & & 7 & & & & & \\
\hline $\begin{array}{l}\text { Heterogeneity: } \mathrm{Chi}^{2}= \\
\text { Test for overall effect: }\end{array}$ & $\begin{array}{l}1.42, \mathrm{df}= \\
=0.20(\mathrm{f}\end{array}$ & $\begin{array}{l}=10(P= \\
=0.84\end{array}$ & $=0.33) ; 1^{2}$ & $=12 \%$ & & & $\begin{array}{ccc}0.01 & 0.1 & 1\end{array}$ & $\begin{array}{c}10 \\
\text { Favours [control] }\end{array}$ \\
\hline
\end{tabular}

(a)

\begin{tabular}{|c|c|c|c|c|c|c|c|c|c|}
\hline Study or Subgroup & $\begin{array}{l}\text { Shoo } \\
\text { Events }\end{array}$ & k & \multicolumn{2}{|c|}{ No Shock } & Weight & $\begin{array}{l}\text { Odds Ratio } \\
\text { M-H, Fixed, } 95 \% \mathrm{Cl}\end{array}$ & \multicolumn{2}{|c|}{$\begin{array}{c}\text { Odds Ratio } \\
\text { M-H, Fixed, } 95 \% \mathrm{Cl}\end{array}$} & \\
\hline AbdulHalim 2004 & 1 & 1 & 0 & 6 & $1.5 \%$ & $39.00[0.53,2883.60]$ & & & \\
\hline Ahlering 1985 & 3 & 7 & 2 & 6 & $32.2 \%$ & $1.50[0.16,14.42]$ & & - & \\
\hline Aswathaman 2008 & 3 & 4 & 6 & 37 & $7.7 \%$ & $15.50[1.37,175.38]$ & & & \\
\hline Cherif 2012 & 6 & 6 & 1 & 24 & $1.2 \%$ & $203.67[7.39,5613.11]$ & & & \\
\hline Dhabalia 2010 & 3 & 6 & 0 & 22 & $3.1 \%$ & $45.00[1.89,1071.31]$ & & & $\longrightarrow$ \\
\hline Dutta 2007 & 7 & 7 & 1 & 13 & $1.8 \%$ & $125.00[4.49,3478.94]$ & & & \\
\hline El-Nahas 2011 & 2 & 6 & 0 & 27 & $3.4 \%$ & $30.56[1.25,746.43]$ & & & \\
\hline Huang 2000 & 6 & 14 & 3 & 34 & $26.2 \%$ & $7.75[1.58,37.96]$ & & & \\
\hline Khaira 2009 & 2 & 8 & 0 & 11 & $8.1 \%$ & $8.85[0.37,213.80]$ & & & \\
\hline Koh 1993 & 1 & 2 & 1 & 2 & $13.1 \%$ & $1.00[0.02,50.40]$ & & & \\
\hline Shokeir 1997 & 3 & 3 & 1 & 17 & $1.8 \%$ & $77.00[2.56,2312.08]$ & & & \\
\hline Total $(95 \% \mathrm{Cl})$ & & 64 & & 199 & $100.0 \%$ & $13.63[6.30,29.51]$ & & & \\
\hline Total events & 37 & & 15 & & & & & & \\
\hline $\begin{array}{l}\text { Heterogeneity: Chi } \\
\text { Test for overall effec }\end{array}$ & $\begin{array}{l}12.20, \mathrm{df} \\
Z=6.63\end{array}$ & $\begin{array}{l}=10(P \\
P<0.0\end{array}$ & $\begin{array}{l}=0.27) ; \\
0001)\end{array}$ & $I^{2}=18^{\circ}$ & & & $\begin{array}{cc}0.01 & 0.1 \\
\text { Favours [experimental] }\end{array}$ & Favours & ${ }_{\text {rol] }}^{100}$ \\
\hline
\end{tabular}

(b)

Fig. 2 Mortality rate comparisons: a, DM vs. no DM; b, Shock vs. no shock; c, Obstructive uropathy vs. no obstruction; d, EN vs. PCD; e, PCD vs. MM; and f, EN vs. MM.

tion [17]. In patients with no DM, urinary albumin is thought to substitute for glucose [17], but glucose is a more favourable substrate for the gas-producing organisms, and thus EPN is more prevalent in the patient with DM.

The most common symptoms are fever and rigors, pyuria, and pain, with a high incidence of leucocytosis. The most common causative organism in laboratory cultures was Escherichia coli, followed by Klebsiella pneumoniae, then Proteus sp. CT was the diagnostic test of choice, with a $100 \%$ detection rate. Therefore, once EPN is suspected, CT must not be delayed to confirm the diagnosis.

We identified that the mortality rate associated with EPN was not as high as previously reported, and the present meta-analysis of previous reports showed a combined mortality rate of $18 \%$. A subgroup analysis showed that although EPN is significantly more com- mon in patients with DM, there was no difference in the mortality rate between patients with and without DM (Table 4). We hypothesise that this is mainly due to the control of DM, initiated in the affected patients by all reporting authors. By managing the DM medically, the risk of death from EPN becomes similar to that of patients without DM. However, if shock was a presenting symptom then the risk of death was significantly higher than if it was not; over $54 \%$ of patients who had shock finally died from EPN (Table 4).

Interestingly, despite it being obvious that renal obstruction would have a worse prognosis, we found that the mortality rate was significantly higher in patients with no obstructive uropathy (Table 4). Again, we postulate that this is probably because clinicians aggressively managed the obstruction, and once relieved, the source of sepsis dissipated, allowing a better outcome. 


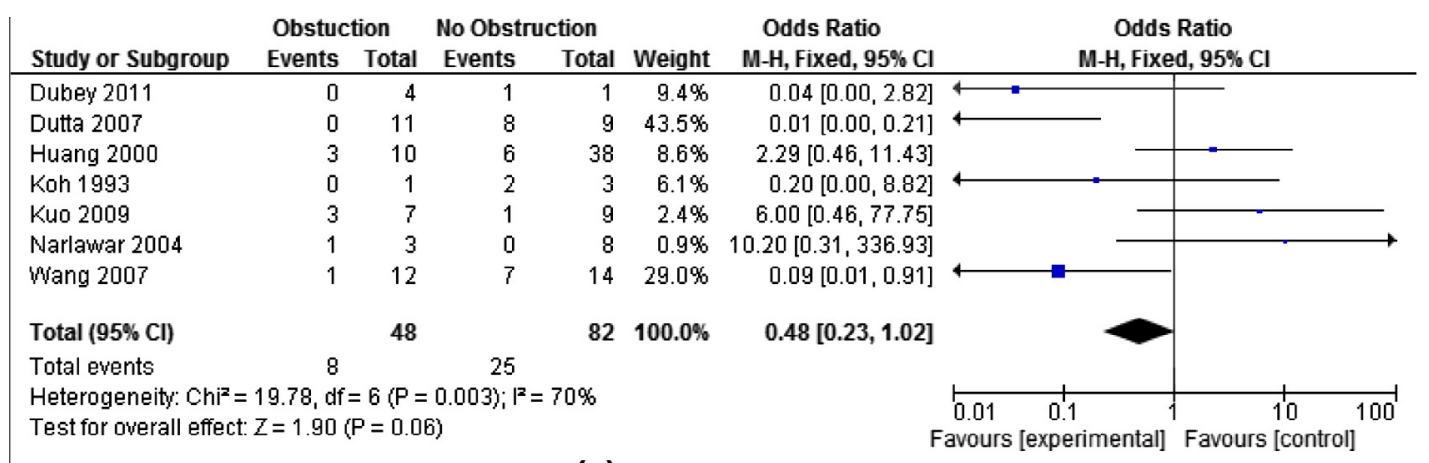

(c)

\begin{tabular}{|c|c|c|c|c|c|c|c|c|}
\hline Study or Subgroup & \multicolumn{2}{|l|}{ EN } & $\begin{array}{l}\text { PCD } \\
\text { Events }\end{array}$ & PCD & \multicolumn{2}{|r|}{ Odds Ratio } & \multicolumn{2}{|c|}{$\begin{array}{c}\text { Odds Ratio } \\
\text { M-H, Fixed, } 95 \% \mathrm{Cl} \\
\end{array}$} \\
\hline AbdulHalim 2004 & 1 & 3 & 0 & 1 & $4.0 \%$ & $1.80[0.04,79.42]$ & & \\
\hline Cherif 2012 & 5 & 14 & 1 & 2 & $10.8 \%$ & $0.56[0.03,10.93]$ & & \\
\hline Derouiche 2008 & 3 & 12 & 0 & 2 & $5.7 \%$ & $1.84[0.07,48.68]$ & & \\
\hline Dubey 2011 & 1 & 1 & 0 & 1 & $1.2 \%$ & $9.00[0.10,831.78]$ & & \\
\hline Dutta 2007 & 1 & 3 & 5 & 10 & $14.8 \%$ & $0.50[0.03,7.45]$ & & \\
\hline El-Nahas 2011 & 1 & 3 & 0 & 14 & $1.3 \%$ & $17.40[0.54,559.54]$ & & \\
\hline Huang 2000 & 0 & 2 & 6 & 33 & $8.5 \%$ & $0.85[0.04,19.83]$ & & \\
\hline Kapoor 2009 & 3 & 7 & 2 & 24 & $5.0 \%$ & $8.25[1.03,66.19]$ & & \\
\hline Khaira 2009 & 2 & 3 & 0 & 5 & $1.4 \%$ & $18.33[0.54,627.20]$ & & \\
\hline Kuzgunbay 2011 & 2 & 5 & 0 & 13 & $1.7 \%$ & $19.29[0.74,500.38]$ & & \\
\hline $\operatorname{Lin} 2012$ & 1 & 1 & 1 & 9 & $1.2 \%$ & $17.00[0.45,648.20]$ & & \\
\hline Soo Park 2006 & 1 & 10 & 0 & 2 & $6.5 \%$ & $0.79[0.02,25.90]$ & & \\
\hline Tang 2000 & 0 & 2 & 4 & 13 & $12.8 \%$ & $0.42[0.02,10.75]$ & & \\
\hline Wan 1998 & 6 & 16 & 3 & 12 & $20.6 \%$ & $1.80[0.34,9.40]$ & & \\
\hline Wang 2007 & 3 & 8 & 0 & 2 & $4.4 \%$ & $3.18[0.12,87.92]$ & & \\
\hline Total $(95 \% \mathrm{Cl})$ & & 90 & & 143 & $100.0 \%$ & $2.54[1.28,5.02]$ & & \\
\hline Total events & 30 & & 22 & & & & & \\
\hline $\begin{array}{l}\text { Heterogeneity: } \mathrm{Ch}^{2}= \\
\text { Test for overall effect }\end{array}$ & $\begin{array}{l}11.17, \text { df } \\
z=2.67\end{array}$ & $\begin{array}{l}=14(\mathrm{P} \\
\mathrm{P}=0.0\end{array}$ & $\begin{array}{l}=0.67) ; \\
108)\end{array}$ & $F^{2}=0 \%$ & & & $\begin{array}{cc}0.01 & 0.1 \\
\text { Favours [experimental] }\end{array}$ & $\begin{array}{cc}10 & 100 \\
\text { Favours [control] }\end{array}$ \\
\hline
\end{tabular}

(d)

Fig. 2 (continued)

There are many different treatment options, with EN, PCD and MM being the major methods. All reports mentioned that all the patients were managed medically, i.e., with antibiotics, diabetic control, and fluids at presentation, before initiating the final treatment option. Nonetheless, we found that $20 \%$ of the patients had EN, $45 \%$ had PCD, 26.6\% had MM, 2.8\% had OD, $4.8 \%$ had PCD and DN, and $0.6 \%$ had MM and DN. There were an additional 17 patients in the PCD + DN group who had a complete resolution of their EPN, but had a DN nonetheless, with no clear reason given.

Comparing the top three treatments, both PCD and MM were associated with significantly lower mortality rates than was EN. Furthermore, the results were similar when comparing these groups of patients to those who also had OD and PCD + DN. We did not compare the groups to those who had $\mathrm{MM}+\mathrm{DN}$ as there were only four patients in the last group.

Comparing the severe to mild classes, there were significantly more patients who died in the severe class than the mild, for both the Wan and Huang classification (Table 4). Furthermore, comparing the severe classes of each classification, there was no significant difference in the death rate, which suggests that both classifications are reliable (Table 4).

\section{Implications for practice}

Based on these results, it is our view that the initial medical therapy, mainly with antibiotics and fluids where needed, and adequate diabetic control, is optimal, and once the diagnosis of EPN is established the clinician should consider either PCD of the abscess, or use complete MM. If the patient is showing signs of shock or end-organ failure that is not responding to $\mathrm{MM}$, then we recommend consultation with an intensive-care specialist for early supportive care and admission to a high-dependency unit, as the evidence suggests these patients have the highest mortality rates. From the available evidence, we also recommend that if PCD or MM 


\begin{tabular}{|c|c|c|c|c|c|c|c|c|}
\hline Study or Subgroup & \multicolumn{2}{|l|}{ PCD } & \multicolumn{2}{|l|}{$\mathrm{MM}$} & \multicolumn{2}{|r|}{ Odds Ratio } & \multicolumn{2}{|c|}{$\begin{array}{c}\text { Odds Ratio } \\
\text { M-H, Fixed, } 95 \% \mathrm{Cl}\end{array}$} \\
\hline Aswathaman 2008 & 6 & 36 & 3 & 5 & $19.1 \%$ & $0.13[0.02,0.98]$ & & \\
\hline Cherif 2012 & 1 & 2 & 1 & 5 & $1.2 \%$ & $4.00[0.12,136.96]$ & & \\
\hline Derouiche 2008 & 0 & 2 & 1 & 4 & $4.1 \%$ & $0.47[0.01,16.89]$ & & \\
\hline Dutta 2007 & 5 & 10 & 0 & 3 & $1.6 \%$ & $7.00[0.29,170.05]$ & & \\
\hline El-Nahas 2011 & 0 & 14 & 1 & 21 & $5.1 \%$ & $0.47[0.02,12.41]$ & & \\
\hline Huang 2000 & 6 & 33 & 2 & 5 & $12.3 \%$ & $0.33[0.05,2.45]$ & & \\
\hline Kapoor 2009 & 2 & 24 & 0 & 4 & $3.3 \%$ & $1.00[0.04,24.55]$ & & \\
\hline Kuo 2009 & 4 & 15 & 0 & 1 & $2.8 \%$ & $1.17[0.04,34.52]$ & & \\
\hline $\operatorname{Lin} 2012$ & 1 & 9 & 0 & 11 & $1.7 \%$ & $4.06[0.15,112.39]$ & & \\
\hline Overa-Posada 2012 & 0 & 3 & 2 & 14 & $4.0 \%$ & $0.71[0.03,18.60]$ & & \\
\hline Soo Park 2006 & 0 & 2 & 2 & 4 & $6.8 \%$ & $0.20[0.01,6.66]$ & & \\
\hline Tang 2000 & 4 & 13 & 2 & 6 & $8.2 \%$ & $0.89[0.11,7.02]$ & & \\
\hline Wan 1998 & 3 & 12 & 6 & 9 & $22.3 \%$ & $0.17[0.02,1.12]$ & & \\
\hline Wang 2007 & 0 & 2 & 4 & 9 & $7.5 \%$ & $0.24[0.01,6.51]$ & & \\
\hline Total $(95 \% \mathrm{Cl})$ & & 177 & & 101 & $100.0 \%$ & $0.57[0.30,1.11]$ & & \\
\hline Total events & 32 & & 24 & & & & & \\
\hline $\begin{array}{l}\text { Heterogeneity: } \mathrm{Chi}^{2}= \\
\text { Test for overall effect: }\end{array}$ & $\begin{array}{l}93, \mathrm{df}=1 \\
=1.64(\mathrm{P}\end{array}$ & $\begin{array}{l}3(P= \\
=0.10\end{array}$ & $0.70) ; 1^{2}=$ & & & & avours [experimental] & Favours [control] \\
\hline
\end{tabular}

(e)

\begin{tabular}{|c|c|c|c|c|c|}
\hline \multirow[b]{2}{*}{ Study or Subgroup } & \multicolumn{2}{|c|}{ EN } & \multicolumn{2}{|c|}{ MM } & \multirow[b]{2}{*}{ Weight } \\
\hline & Events & Total & Events & Total & \\
\hline Cherif 2012 & 5 & 14 & 1 & 5 & $5.9 \%$ \\
\hline Derouiche 2008 & 3 & 12 & 1 & 4 & $7.1 \%$ \\
\hline Dhabalia 2010 & 3 & 4 & 0 & 22 & $0.3 \%$ \\
\hline Dubey 2011 & 1 & 1 & 0 & 3 & $0.5 \%$ \\
\hline Dutta $200 ?$ & 1 & 3 & 0 & 3 & $2.0 \%$ \\
\hline El-Nahas 2011 & 1 & 3 & 1 & 21 & $1.0 \%$ \\
\hline Huang 2000 & 2 & 2 & 2 & 5 & $1.7 \%$ \\
\hline Kapoor 2009 & 3 & 7 & 0 & 4 & $2.2 \%$ \\
\hline Khaira 2009 & 2 & 3 & 0 & 11 & $0.6 \%$ \\
\hline Kuzgunbay 2011 & 2 & 5 & 0 & 6 & $1.7 \%$ \\
\hline $\operatorname{Lin} 2012$ & 1 & 1 & 0 & 11 & $0.2 \%$ \\
\hline Shokeir 1997 & 3 & 19 & 1 & 1 & $14.1 \%$ \\
\hline Soo Park 2006 & 1 & 10 & 2 & 4 & $16.1 \%$ \\
\hline Tang 2000 & 2 & 2 & 2 & 6 & $1.6 \%$ \\
\hline Wan 1998 & 6 & 16 & 6 & 9 & $30.1 \%$ \\
\hline Wang 2007 & 3 & 8 & 4 & 9 & $14.8 \%$ \\
\hline Total $(95 \% \mathrm{Cl})$ & & 110 & & 124 & $100.0 \%$ \\
\hline Total events & 39 & & 20 & & \\
\hline $\begin{array}{l}\text { Heterogeneity: Chi } \\
\text { Test for overall effec }\end{array}$ & $\begin{array}{l}9.22, \mathrm{df} \\
=2.36\end{array}$ & $\begin{array}{l}=15(P \\
P=0.0\end{array}$ & $\begin{array}{l}=0.02) ; \\
2)\end{array}$ & & \\
\hline
\end{tabular}

(f)

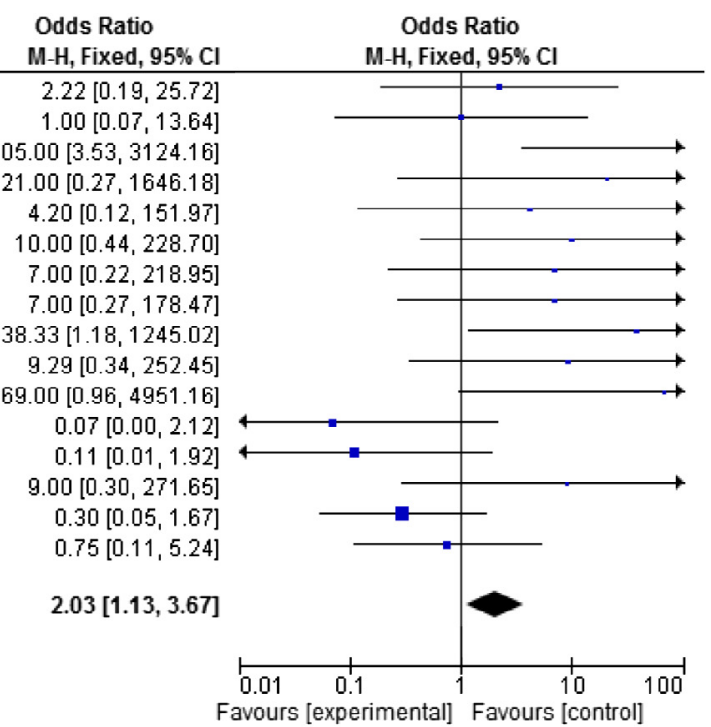

Favours [experimental] Favours [control]

Fig. 2 (continued)

is not improving the patient's condition, then OD must be considered before considering a nephrectomy. To this end, based on the evidence, we constructed a flow chart to aid clinicians in managing EPN (Fig. 3).

Furthermore, as there are two schemes for classifying EPN that have been widely adopted, based on imaging findings, we recommend classifying EPN into either one of these schemes, as we found no significant difference in the final outcome for either. Although the patient's condition should direct the management, classifying into mild or severe EPN would also be an aid to management.

\section{The strengths and limitations of the review}

The main limitation of this review is the type of studies included in the meta-analysis. All the studies were case series reporting their centre's experience of managing EPN. However, for such a rare disease, in emergency circumstances, it is difficult to include patients into well-formulated trials, and we must therefore rely on this type of report for evidence. Collating them and using meta-analyses of the results strengthens the level of evidence provided. Furthermore, the studies were reported from various centres worldwide, which adds some variability to the data, thus allowing for the generalisation of the end results.

Nonetheless, this review was impartial and conducted systematically and methodically in keeping with the Cochrane standards. This report represents the evidence available, reporting on the incidence, risk factors associated with, and investigations, treatment and mortality rates of EPN. 


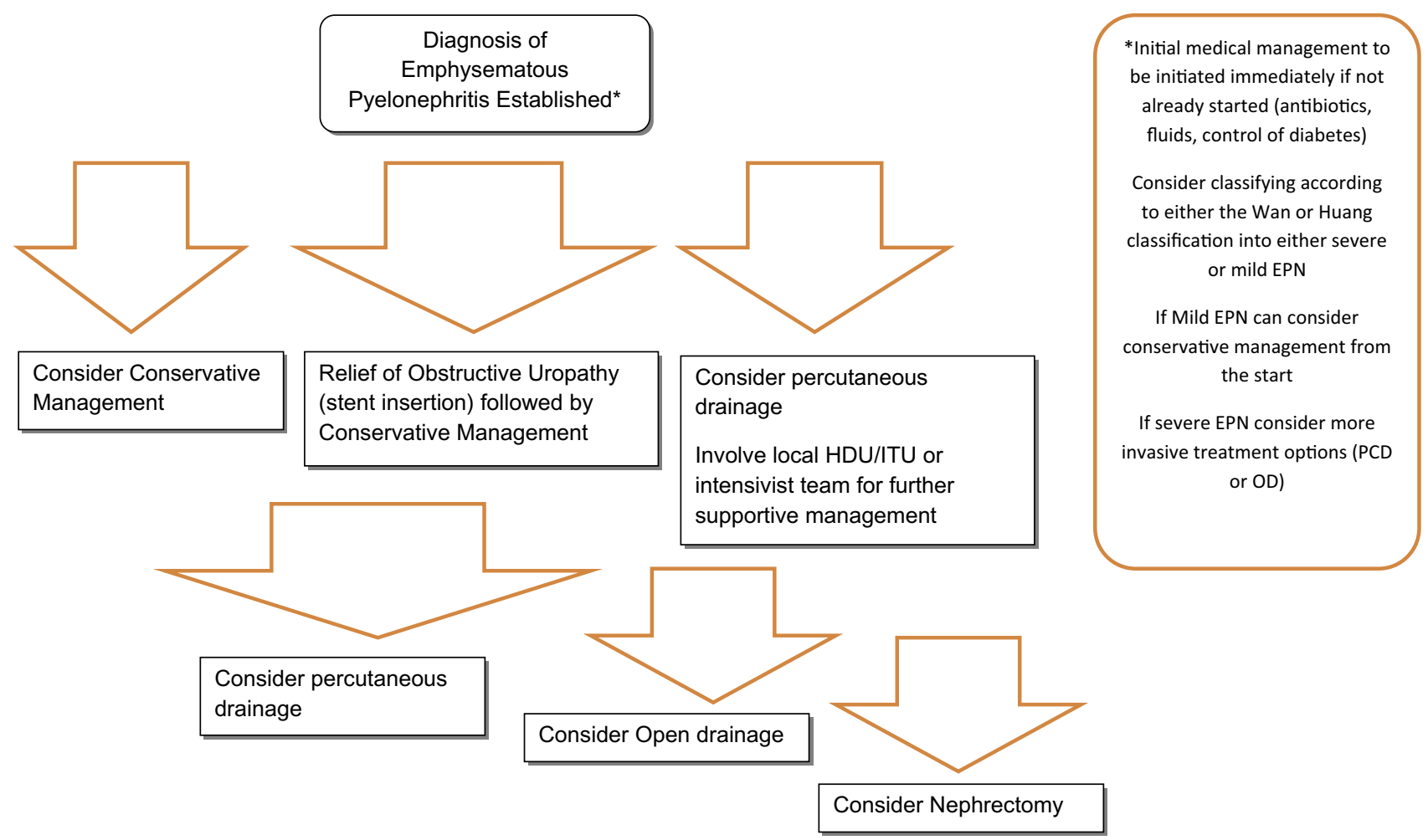

Fig. 3 Recommendations for managing EPN.

In conclusion, the results of this systematic review and meta-analysis show that EPN has an overall mortality rate of about $18 \%$. PCD and MM are associated with significantly higher survival rates than EN, and therefore EN should only be considered if the patients persistently do not improve despite other treatments. Survival is improved if diabetic management is initiated immediately, and aggressive treatments of sepsis are also started as soon as possible.

The best diagnostic method is CT, which also aids in classifying EPN. Severe EPN is associated with a high mortality rate, and therefore more aggressive treatment is recommended.

\section{Conflict of interest}

None.

\section{Source of funding}

None.

\section{Acknowledgement}

Omar M. Aboumarzouk acknowledges Dr. Isra Ashi, for her guidance and support.

\section{References}

[1] Narlawar RS, Raut AA, Nagar A, Hira P, Hanchate V, Asrani A. Imaging features and guided drainage in emphysematous pyelonephritis: a study of 11 cases. Clin Radiol 2004;59:192-7.

[2] Shokeir AA, El-Azab M, Mohsen T, El-Diasty T. Emphysematous pyelonephritis: a 15-year experience with 20 cases. Urology 1997:49:343-6.

[3] Tang HJ, Li CM, Yen MY, Chen YS, Wann SR, Lin HH, et al. Clinical characteristics of emphysematous pyelonephritis. $J$ Microbiol Immunol Infect 2001;34:125-30.

[4] Wan YL, Lee TY, Bullard MJ, Tsai CC. Acute gas-producing bacterial renal infection. correlation between imaging findings and clinical outcome. Radiology 1996;198:433-8.

[5] Somani BK, Nabi G, Thorpe P, Hussey J, Cook J, N'Dow J. Is percutaneous drainage the new gold standard in the management of emphysematous pyelonephritis? Evidence from a systematic review. J Urol 2008;179:1844-9.

[6] El-Nahas AR, Shokeir AS, Eziyi AK, Barakat TS, Tijani KH, ElDiasty $\mathrm{T}$, et al. Kidney preservation protocol for management of emphysematous pyelonephritis: treatment modalities and followup. Arab J Urol 2011;9:185-9.

[7] Chen MT, Huang CN, Chou YH, Huang CH, Chiang CP, Liu GC. Percutaneous drainage in the treatment of emphysematous pyelonephritis: 10-year experience. J Urol 1997;157:1569-73.

[8] Wang JM, Lim HK, Pang KK. Emphysematous pyelonephritis. Scand J Urol Nephrol 2007;41:223-9.

[9] Nagappan R, Kletchko S. Bilateral emphysematous pyelonephritis resolving to medical therapy. J Intern Med 1992;232:77-80.

[10] Lin YC, Lin HD, Lin LY. Risk factors of renal failure and severe complications in patients with emphysematous pyelonephritis - a single-center 15-year experience. Am J Med Sci 2012;343:186-91. 
[11] Kolla PK, Madhav D, Reddy S, Pentyala S, Kumar P, Pathapati RM. Clinical profile and outcome of conservatively managed emphysematous pyelonephritis. ISRN Urol 2012;2012:931982.

[12] Kapoor R, Muruganandham K, Gulia AK, Singla M, Agrawal S, Mandhani A, et al. Predictive factors for mortality and need for nephrectomy in patients with emphysematous pyelonephritis. BJU Int 2010;105:986-9.

[13] Olvera-Posada D, Garcia-Mora A, Culebro-Garcia C, CastillejosMolina R, Sotomayor M, Feria-Bernal G, et al. Prognostic factors in emphysematous pyelonephritis. Actas Urol Esp 2013;37: 228-32.

[14] Wan YL, Lo SK, Bullard MJ, Chang PL, Lee TY. Predictors of outcome in emphysematous pyelonephritis. J Urol 1998;159: 369-73.

[15] Kuo CY, Lin CY, Chen TC, Lin WR, Lu PL, Tsai JJ, et al. Clinical features and prognostic factors of emphysematous urinary tract infection. J Microbiol Immunol Infect 2009;42: 393-400.

[16] Khaira A, Gupta A, Rana DS, Bhalla A, Khullar D. Retrospective analysis of clinical profile prognostic factors and outcomes of 19 patients of emphysematous pyelonephritis. Int Urol Nephrol 2009;41:959-66.

[17] Kuzgunbay B, Turunc T, Tokmak N, Dirim A, Aygun C, Ozkardes H. Tailored treatment approach for emphysematous pyelonephritis. Urol Int 2011;86:444-7.

[18] Huang JJ, Tseng CC. Emphysematous pyelonephritis. clinicoradiological classification, management, prognosis, and pathogenesis. Arch Intern Med 2000;160:797-805.

[19] Kuo YT, Chen MT, Liu GC, Huang CN, Huang CL, Huang CH. Emphysematous pyelonephritis. Imaging, diagnosis and followup. Kaohsiung J Med Sci 1999;15:159-70.

[20] Aswathaman K, Gopalakrishnan G, Gnanaraj L, Chacko NK, Kekre NS, Devasia A. Emphysematous pyelonephritis. Outcome of conservative management. Urology 2008;71:1007-9.

[21] Dhabalia JV, Nelivigi GG, Kumar V, Gokhale A, Punia MS, Pujari N. Emphysematous pyelonephritis. Tertiary care center experience in management and review of the literature. Urol Int 2010;85:304-8.

[22] Higgins JP, Thompson SG, Deeks JJ, Altman DG. Measuring inconsistency in meta-analyses. BMJ 2003;327:557-60.

[23] Higgins, J.P.G.S., Cochrane Handbook for Systematic Reviews of Interventions: The Cochrane Collaboration (2011). Available from: <www.cochrane-handbook.org > .

[24] Abdul-Halim H, Kehinde EO, Abdeen S, Lashin I, Al-Hunayan KA, Al-Awadi KA. Severe emphysematous pyelonephritis in diabetic patients. Diagnosis and aspects of surgical management. Urol Int 2005;75:123-8.

[25] Ahlering TE, Boyd SD, Hamilton CL, Bragin SD, Chandrasoma G, Lieskovsky G, et al. Emphysematous pyelonephritis: a 5-year experience with 13 patients. J Urol 1985;134:1086-8.

[26] Best CD, Terris MK, Tacker JR, Reese JH. Clinical and radiological findings in patients with gas forming renal abscess treated conservatively. J Urol 1999;162:1273-6.

[27] Bjurlin MA, Hurley SD, Kim DY, Cohn MR, Jordan MD, Kim $\mathrm{R}$, et al. Clinical outcomes of nonoperative management in emphysematous urinary tract infections. Urology 2012;79:1281-5.

[28] Chan PH, Kho VK, Lai SK, Yang CH, Chang HC, Chiu B, et al. Treatment of emphysematous pyelonephritis with broad-spectrum antibacterials and percutaneous renal drainage: an analysis of 10 patients. J Chin Med Assoc 2005;68:29-32.

[29] Cherif M, Kerkeni W, Bouzouita A, Selmi MS, Derouiche A, Ben Slama MR, et al. Emphysematous pyelonephritis. Epidemiological, clinical, biological, bacteriological, radiological, therapeutic and prognostic features. Retrospective study of 30 cases. Tunis Med 2012;90:725-9.
[30] Derouiche A, Ouni A, Agrebi A, Slama A, Ben Slama MR, Chebil M. Management of emphysematous pyelonephritis based on a series of 21 cases. Prog Urol 2008;18:102-7.

[31] Dubey IB, Agrawal V, Jain BK. Five patients with emphysematous pyelonephritis. Iran J Kidney Dis 2011;5:204-6.

[32] Dutta P, Bhansali A, Singh SK, Gupta KL, Bhat MH, Masoodi SR, et al. Presentation and outcome of emphysematous renal tract disease in patients with diabetes mellitus. Urol Int 2007;78:13-22.

[33] Goel T, Reddy S, Thomas J. Emphysematous pyelonephritis with calculus: management strategies. Indian J Urol 2007;23:250-2 [J Urol Soc India].

[34] Koh KB, Lam HS, Lee SH. Emphysematous pyelonephritis. Drainage or nephrectomy? Br J Urol 1993;71:609-11.

[35] Mokabberi R, Ravakhah K. Emphysematous urinary tract infections. Diagnosis, treatment and survival (case review series). Am J Med Sci 2007;333:111-6.

[36] Roy C, Pfleger DD, Tuchmann CM, Lang HH, Saussine CC, Jacqmin D. Emphysematous pyelitis: findings in five patients. Radiology 2001;218:647-50.

[37] Soo Park B, Lee SJ, Wha Kim Y, Sik Huh II J, Kim J, Chang SG. Outcome of nephrectomy and kidney-preserving procedures for the treatment of emphysematous pyelonephritis. Scand J Urol Nephrol 2006; $40: 332-8$.

[38] Akpek S, Turgut T, Ozdemir H, Ilgit ET, Isik S. Emphysematous pyelonephritis: fatal outcome during percutaneous drainage. Eur J Radiol 1998;26:287-9.

[39] Falagas ME, Alexiou VG, Giannopoulou KP, Siempos II. Risk factors for mortality in patients with emphysematous pyelonephritis: a meta-analysis. J Urol 2007; 178:880-5.

[40] Grozel F, Berthezene Y, Guerin C, Tran-Minh VA, Croisille M. Bilateral emphysematous pyelonephritis resolving to medical therapy. Demonstration by US and CT. Eur Radiol 1997;7: 844-6.

[41] Kauzlaric D, Barmeir E. Sonography of emphysematous cystitis. $J$ Ultrasound Med 1985:4:319-20.

[42] McCabe JB, Mc-Ginn Merritt W, Olsson D, Wright V, Camporesi EM. Emphysematous cystitis. Rapid resolution of symptoms with hyperbaric treatment: a case report. J Undersea Hyperb Med 2004;31:281-4.

[43] Michaeli J, Mogle P, Perlberg S, Heiman S, Caine M. Emphysematous pyelonephritis. J Urol 1984;131:203-8.

[44] Mydlo JH, Maybee GJ, Ali-Khan MM. Percutaneous drainage and/or nephrectomy in the treatment of emphysematous pyelonephritis. Urol Int 2003;70:147-50.

[45] Quint HJ, Drach GW, Rappaport WD, Hoffmann CJ. Emphysematous cystitis. A review of the spectrum of disease. J Urol 1992;147:134-7.

[46] Ramanathan V, Nguyen PT, Van Nguyen P, Khan A, Musher D. Successful medical management of recurrent emphysematous pyelonephritis. Urology 2006;67(623):e11-3.

[47] Rathod KR, Narlawar RS, Garg A, Lolge S. Percutaneous conservative management of emphysematous pyelonephritis. $J$ Postgrad Med 2001;47:66.

[48] Rocca JM, McClure J. Cystitis emphysematosa. Br J Urol 1985;57:585.

[49] Singh I, Pachisia SS, Kumar S, Arora VK, Kumar P. Emphysematous pyelonephritis. A consequence of adenocarcinoma of urinary bladder in a nondiabetic patient. J Postgrad Med 2005;51: $324-5$.

[50] Thomas AA, Lane BR, Thomas AZ, Remer EM, Campbell SC, Shoskes DA. Emphysematous cystitis: a review of 135 cases. BJU Int 2007;100:17-20. 